\title{
Efficacy and safety of NVA237 versus placebo and tiotropium in patients with COPD: the GLOW2 study
}

\author{
Edward Kerwin*, Jacques Hébert", Nicola Gallagher", Carmen Martin \%, \\ Tim Overend", Vijay K.T. Alagappan ${ }^{+}$, Yimeng Lu+ and Donald Banerji ${ }^{+}$
}

ABSTRACT: NVA237 (glycopyrronium bromide) is a once-daily long-acting muscarinic antagonist (LAMA) in development for chronic obstructive pulmonary disease (COPD). The GLycopyrronium bromide in COPD airWays clinical Study 2 (GLOW2) evaluated the efficacy and safety of NVA237 in moderate-to-severe COPD over 52 weeks.

Patients were randomised 2:1:1 to NVA237 $50 \mu \mathrm{g}$, placebo or open-label tiotropium $18 \mu \mathrm{g}$ for 52 weeks. Primary end-point was trough forced expiratory volume in $1 \mathrm{~s}$ (FEV1) at 12 weeks.

1,066 patients were randomised, 810 completed the study. At week 12, trough FEV 1 increased significantly by $97 \mathrm{~mL}$ with NVA237 (95\% Cl 64.6-130.2; p<0.001) and $83 \mathrm{~mL}$ with tiotropium (95\% CI 45.6-121.4; $p<0.001)$. Compared with placebo, NVA237 produced significant improvements in dyspnoea (Transition Dyspnoea Index at week 26; $p=0.002$ ) and health status (St George's Respiratory Questionnaire at week 52; $p<0.001)$. NVA237 significantly reduced the risk of moderate-to-severe COPD exacerbations by $34 \%(p=0.001)$ and the use of rescue medication $(p=0.039)$, versus placebo. NVA237-placebo and tiotropium-placebo differences were comparable for all outcomes. Safety profiles were similar across groups.

NVA237 $50 \mu \mathrm{g}$ provided significant improvements in lung function, dyspnoea, health status, exacerbations and rescue medication use, versus placebo, and was comparable to tiotropium. NVA237 can potentially be an alternative choice of LAMA for COPD patients.

KEYWORDS: Bronchodilator, chronic obstructive pulmonary disease, glycopyrronium bromide, long-acting muscarinic antagonist, NVA237, tiotropium

hronic obstructive pulmonary disease (COPD) is a preventable and treatable chronic disease, but is frequently underdiagnosed and under-treated in clinical practice $[1,2]$. Inhaled bronchodilators, including longacting muscarinic antagonists (LAMAs), are the mainstay of the current management guidelines for COPD and are recognised to improve symptoms and health status [2].

NVA237 is a once-daily (q.d.) dry-powder formulation of the LAMA glycopyrronium bromide, in development for the treatment of COPD. Results from preclinical and phase II studies have demonstrated the safety and efficacy of NVA237 [3-7]. In a phase II study comparing the efficacy of multiple doses of NVA237 with placebo and tiotropium $18 \mu \mathrm{g}$ q.d. [6], NVA237 $50 \mu \mathrm{g}$ q.d. and tiotropium showed comparable and statistically significant improvements in mean trough forced expiratory volume in $1 \mathrm{~s}$ (FEV1) versus placebo on days 1 and 7 (all $p<0.0001$ ). Additionally, FEV1 on day 1 was significantly higher $(p<0.05)$ with NVA237 $50 \mu \mathrm{g}$ versus tiotropium from $5 \mathrm{~min}$ up to 2 and $4 \mathrm{~h}$ post-dose.

In the phase III GLycopyrronium bromide in COPD airWays clinical study 1 (GLOW1) in patients with moderate-to-severe COPD, NVA237 $50 \mu \mathrm{g}$ q.d. produced rapid and significant improvements in trough FEV1, compared with placebo, which were apparent on day 1 and sustained through week 26 [8]. Significant improvements were also observed over 26 weeks in dyspnoea measured by Transition Dyspnoea Index (TDI), health status measured by St George's Respiratory Questionnaire (SGRQ), risk of moderate-to-severe COPD exacerbations, and rescue medication use,
AFFILIATIONS

${ }^{*}$ Clinical Research Institute of Southern Oregon, PC, Medford, OR, and

${ }^{+}$Novartis Pharmaceuticals

Corporation, East Hanover, NJ, USA

${ }^{\#}$ Centre de Recherche Appliquée en Allergie de Québec, Québec, QC, Canada.

'Novartis Horsham Research Centre, Horsham, UK.

CORRESPONDENCE

E. Kerwin

3860 Crater Lake Avenue

Medford

OR 97504

USA

E-mail: ekerwin@

allergyasthmaso.com

Received:

March 062012

Accepted after revision:

June 142012

First published online:

July 262012

This article was modified in April 2016 to correct errors in the licence information. 
versus placebo. NVA237 was well tolerated and had an acceptable safety profile, with a low incidence of typical anticholinergic adverse effects [8].

Tiotropium, established as a safe and effective bronchodilator, is the only licensed LAMA available currently for COPD patients and is widely used worldwide. The objective of the phase III GLOW2 study was to evaluate the efficacy and safety of NVA237 $50 \mu \mathrm{g}$ q.d. in patients with moderate-to-severe COPD compared with placebo and with tiotropium (as a reference comparator) over a longer treatment period of 52 weeks.

\section{METHODS}

More details are provided in the online supplement.

\section{Patients}

Males and females $\geqslant 40$ yrs of age, with a smoking history of $\geqslant 10$ pack-yrs, a diagnosis of moderate-to-severe stable COPD (as defined in the 2008 Global Initiative for Chronic Obstructive Lung Disease (GOLD) guidelines) [9], post-bronchodilator FEV1 $\geqslant 30 \%$ and $<80 \%$ of the predicted normal, and post-bronchodilator FEV1/forced vital capacity (FVC) $<0.70$ were enrolled.

Exclusion criteria included lower respiratory tract infection in the 6 weeks prior to screening; concomitant pulmonary disease (such as pulmonary tuberculosis or clinically significant bronchiectasis); history of asthma, malignancy of any organ system/ long QT syndrome or QTc $>450 \mathrm{~ms}$ (males) or $>470$ (females) at screening, symptomatic prostatic hyperplasia, bladder-neck obstruction, moderate/severe renal impairment, urinary retention, narrow-angle glaucoma, a known history of $\alpha_{1}$-antitrypsin deficiency; participation in the active phase of a supervised pulmonary rehabilitation programme; and contraindications for tiotropium or ipratropium or history of adverse reactions to inhaled anticholinergics.

\section{Study design and treatment}

This was a multicentre, double-blind, placebo-controlled with open-label tiotropium arm, parallel group study. Patients were randomised to receive NVA237 $50 \mu \mathrm{g}$ q.d. or placebo (both delivered via a low-resistance single-dose dry-powder inhaler (the Breezhaler ${ }_{\circledR}$ device; Novartis, Basel, Switzerland); $50 \mu \mathrm{g}$ refers to the quantity of the glycopyrronium moiety present in the capsule, which corresponds to a delivered dose of $44 \mu \mathrm{g}$ ), or open-label tiotropium $18 \mu \mathrm{g}$ (delivered via the HandiHaler ${ }^{\circledR}$ device; Boehringer Ingelheim, Ingelheim, Germany) in the morning between $08: 00$ and 11:00 $\mathrm{h}$, in a ratio of 2:1:1 for a period of 52 weeks, following a washout period (of up to 7 days) and a 14-day run-in period (fig. 1).

Patients were to discontinue taking long-acting bronchodilator therapy before starting the run-in period (for at least 7 days for LAMAs or $48 \mathrm{~h}$ for long-acting $\beta_{2}$-agonists (LABAs) or LABA/ inhaled corticosteroid (ICS) combinations). Patients using LABA/ICS combinations were switched to an equivalent dose of ICS as monotherapy plus salbutamol/albuterol as rescue medication for at least $48 \mathrm{~h}$ prior to screening. The ICS doses had to remain stable during the screening period; patients who failed screening for this reason could be re-screened if the ICS dose had been stable for 1 month. Patients were expected to remain on the same dose of ICS throughout the study.

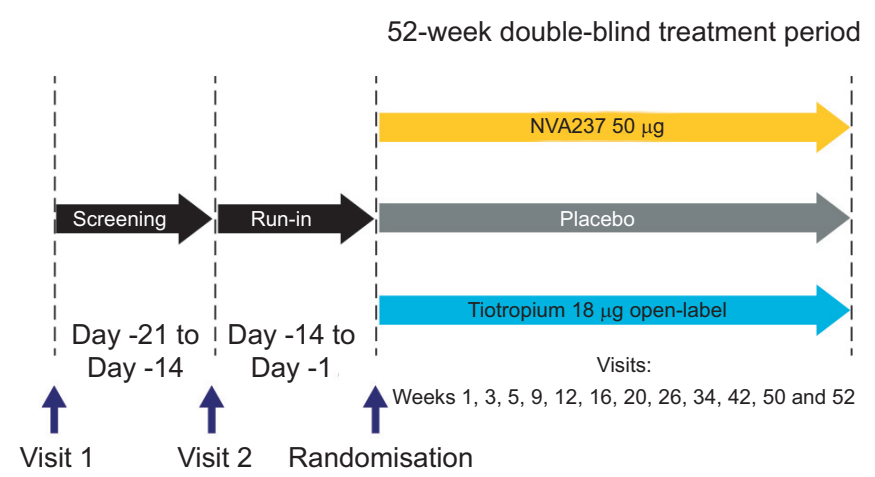

FIGURE 1. GLOW2 study design.

In addition to the study treatment, concomitant medications (inhaled or intranasal corticosteroids and $\mathrm{H} 1$ antagonists) were permitted in patients who had been stabilised on a recommended and constant dose prior to study entry. Patients were provided with a salbutamol/albuterol inhaler to be used as rescue medication during the study.

\section{Efficacy assessments}

Efficacy was assessed in the full analysis set (FAS) which included all randomised patients who received at least one dose of the study drug; patients in the FAS were analysed according to the treatment to which they were randomised.

The primary efficacy variable was trough FEV1 (defined as the mean of the $23 \mathrm{~h} 15 \mathrm{~min}$ and the $23 \mathrm{~h} 45 \mathrm{~min}$ post-dose values) following 12 weeks of treatment. Key secondary variables were dyspnoea measured using the TDI at week 26 and health status according to the total score on SGRQ at week 52. Important secondary variables were time to first moderate or severe COPD exacerbation and mean daily rescue medication use over 52 weeks. Additional secondary variables included trough FEV1, trough FVC and inspiratory capacity at the end of day 1 and at weeks 26 and 52, serial spirometry in a subset of patients (in study sites which had the facilities and personnel for making these measurements) on day 1 and weeks 12 and 52, and the rate of COPD exacerbations in the 52-week treatment period.

Comparison of open-label tiotropium $18 \mu \mathrm{g}$ to placebo and NVA237 in terms of all the end-points was also an additional variable; the study was not powered to show statistical superiority of NVA237 versus tiotropium.

\section{Safety assessments}

The safety population included all patients who received at least one dose of the study treatment; patients were analysed according to the treatment they received. Safety was assessed by recording treatment-emergent adverse events and monitoring vital signs (pulse rate and systolic and diastolic blood pressure), and laboratory analyses (haematology, clinical chemistry and urinalysis).

\section{Statistics}

The primary efficacy variable (trough FEV1 at week 12) was analysed using a mixed model, with treatment as a fixed effect and baseline FEV1 and FEV1 reversibility (in response to $80 \mu \mathrm{g}$ ipratopium bromide), and baseline ICS use (yes/no) acting as 
covariates. To reflect the randomisation scheme, the model also included baseline smoking status (current/ex-smoker) and region as fixed effects with centre nested within region as a random effect.

TDI and SGRQ scores and rescue use were analysed with the same mixed model as in the primary efficacy analysis, with baseline SGRQ score, baseline dyspnoea index and baseline rescue use replacing baseline FEV1 as covariates, respectively.

The time to first exacerbation was displayed for each treatment group with a Kaplan-Meier curve, and analysed using a Cox regression model, which included terms for treatment, baseline inhaled corticosteroid use (yes/no), daily total symptom score, COPD exacerbation history, FEV1 reversibility, smoking history and region.

\section{RESULTS}

\section{Patient disposition and baseline characteristics}

A total of 1,066 patients were randomised to one of the three treatment groups in a 2:1:1 ratio (NVA237:placebo:tiotropium); $76 \%$ patients completed the study (fig. 2). A higher percentage of patients in the placebo group discontinued (28.3\%), compared with the patients in NVA237 (22.3\%) and tiotropium groups $(23.1 \%)$. Baseline characteristics were broadly similar between the treatment groups (table 1). A majority of the patients had moderate COPD $(64 \%)$ and $\sim 26 \%$ of the patients had a documented history of exacerbations in the year prior to enrolment.

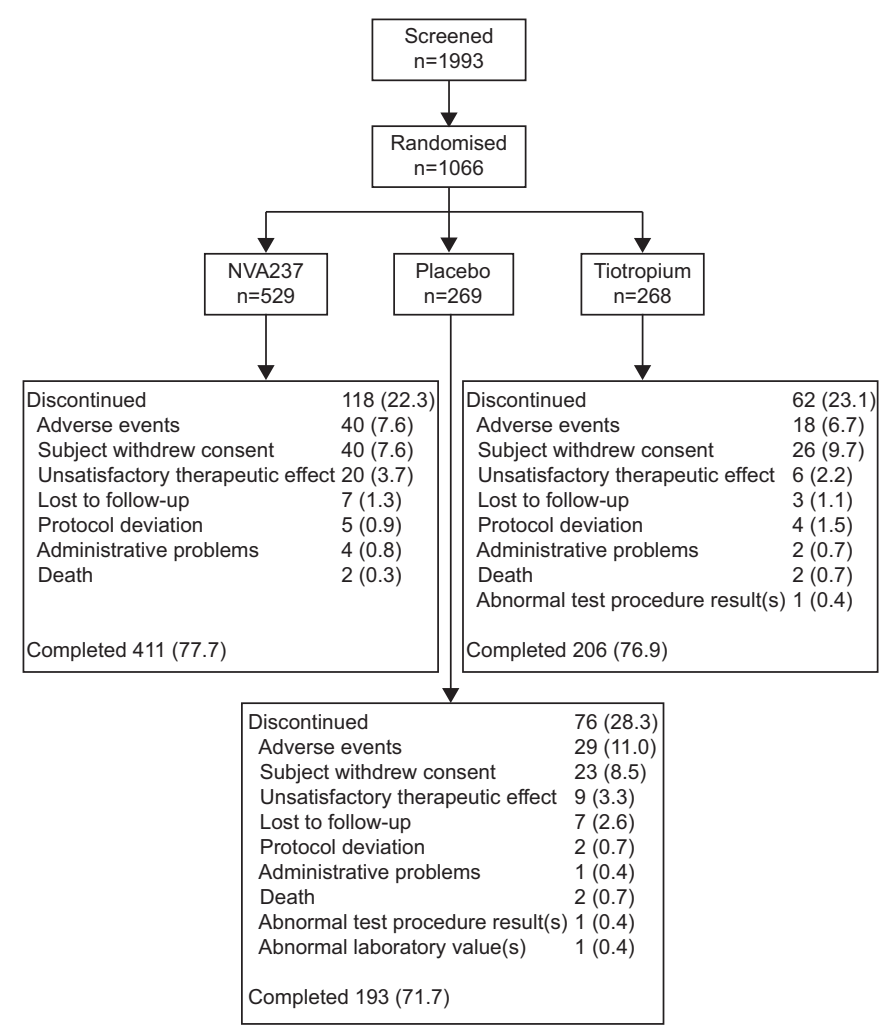

FIGURE 2. Patient disposition.

\section{Efficacy}

Spirometry

Least squares mean (LSM) trough FEV1 at week 12 (primary end-point) was significantly higher in patients receiving NVA237 $50 \mu \mathrm{g}$ q.d. and tiotropium $18 \mu \mathrm{g}$ q.d. compared with patients receiving placebo, with a treatment difference of $97 \mathrm{~mL}$ (95\% CI 64.6-130.2; p<0.001) and $83 \mathrm{~mL}(95 \%$ CI 45.6-121.4; $\mathrm{p}<0.001$ ), respectively (fig. 3). Trough FEV1 at the end of day 1 and at weeks 26 and 52 in the NVA237 group was significantly higher versus placebo and comparable to tiotropium (fig. 3; table 2). At the end of day 1 and at weeks 26 and 52, compared with placebo, the treatment difference in favour of NVA237 was 91, 134 and $108 \mathrm{~mL}$, respectively (all $\mathrm{p}<0.001$ ), while the difference in favour of tiotropium was 83,84 and $89 \mathrm{~mL}$, respectively (all p<0.001). Furthermore, at week 26, NVA237 significantly improved trough FEV1 by $50 \mathrm{~mL}$ more than tiotropium (treatment difference: 134 versus $84 \mathrm{~mL}$; $\mathrm{p}$ <0.007). At the other time points, the improvement in trough FEV1 provided by NVA237 was comparable to the improvement provided by tiotropium, but the difference was not statistically significant.

NVA237 provided rapid bronchodilation following the first dose on day 1, with significantly higher FEV1 at all time points from 5 min to 4 h post-dose, compared with placebo $(\mathrm{p}<0.001)$ and with tiotropium $(\mathrm{p}<0.01$; online supplement fig. $\mathrm{S} 1)$. On day 1, the FEV1 LSM treatment difference for NVA237-placebo and tiotropium-placebo was 87 and $45 \mathrm{~mL}$ at $5 \mathrm{~min}$, respectively, and 143 and $78 \mathrm{~mL}$ at $15 \mathrm{~min}$, respectively (all $\mathrm{p}<0.001$; table 2). Peak FEV1 and FEV1 area under the curve (AUC) from 0 to $4 \mathrm{~h}\left(\mathrm{AUC}_{0-4 \mathrm{~h}}\right)$ post-dose in the NVA237 group was significantly superior to placebo and tiotropium (all $\mathrm{p}<0.001$ ) at day 1 , was significantly superior to placebo $(p<0.001)$ and tiotropium $(p<0.01)$ at week 26 , and was comparable to tiotropium at weeks 12 and 52 (table 2).

The bronchodilation produced by NVA237 was sustained over the 24-h period on day 1 and weeks 12 and 52, as seen in a subpopulation of patients (the serial spirometry group; $n=299$ ). FEV1 $\mathrm{AUC}_{0-12 \mathrm{~h}}$ with NVA237 was significantly $(\mathrm{p}<0.001)$ greater than placebo at day 1 and weeks 12 and 52, significantly greater than tiotropium $(\mathrm{p}<0.05)$ at week 52 and comparable to tiotropium at day 1 and week 12 (table 2). FEV1 $\mathrm{AUC}_{0-24} \mathrm{~h}$ with NVA237 was significantly greater $(p<0.001)$ than placebo at weeks 12 and 52 and significantly greater than tiotropium at week 52 ( $\mathrm{p}<0.05$; table 2$)$. Serial spirometry also demonstrated significantly higher values for FEV1 throughout the 24-h periods on day 1 and at weeks 12 and 52 in patients receiving NVA237, compared with placebo (fig. 4).

Inspiratory capacity was significantly higher in the NVA237 group versus placebo $(\mathrm{p}<0.001$; except one pre-dose measurement at $-20 \mathrm{~min}$ at week $52, \mathrm{p}=0.053$ ), and was comparable to that in the tiotropium group, at almost all evaluated time points on day 1 and weeks 12 and 52 (online supplement table S1). Trough FVC was also significantly greater in the NVA237 and tiotropium patient groups versus placebo at day 1 and weeks 12, 26 and 52 ( $<<0.001$; online supplement table S2).

\section{Dyspnoea}

NVA237 $50 \mu \mathrm{g}$ q.d. significantly improved the TDI focal score at week 26 (2.13) compared with placebo (1.32), with a LSM 
TABLE 1 Baseline demographics and clinical characteristics (safety population)

\begin{tabular}{|c|c|c|c|}
\hline & NVA237 $50 \mu \mathrm{g}$ q.d. & Placebo & Tiotropium $18 \mu \mathrm{g}$ q.d. \\
\hline Subjects $n$ & 525 & 268 & 267 \\
\hline \multicolumn{4}{|l|}{ Sex } \\
\hline Male & $339(64.6)$ & $173(64.6)$ & $168(62.9)$ \\
\hline Female & $186(35.4)$ & $95(35.4)$ & $99(37.1)$ \\
\hline Black & $20(3.8)$ & $10(3.7)$ & $12(4.5)$ \\
\hline Asian & $26(5.0)$ & $12(4.5)$ & $15(5.6)$ \\
\hline Other & $20(3.8)$ & $10(3.7)$ & $8(3.0)$ \\
\hline Body mass index $\mathrm{kg} \cdot \mathrm{m}^{-2}$ & $27.9 \pm 6.2$ & $27.5 \pm 6.2$ & $27.7 \pm 6.4$ \\
\hline \multicolumn{4}{|l|}{ Severity of COPD (GOLD 2008) } \\
\hline \multicolumn{4}{|l|}{ Baseline COPD exacerbation history ${ }^{\#}$} \\
\hline 0 exacerbations & $377(71.8)$ & $206(76.9)$ & $195(73.0)$ \\
\hline 1 exacerbations & $113(21.5)$ & $43(16.0)$ & $55(20.6)$ \\
\hline$\geqslant 2$ exacerbations & $35(6.7)$ & $19(7.1)$ & $17(6.4)$ \\
\hline ICS use at baseline & $293(55.8)$ & $137(51.1)$ & $138(51.7)$ \\
\hline \multicolumn{4}{|l|}{ Smoking history } \\
\hline Ex-smoker & $287(54.7)$ & $144(53.7)$ & $149(55.8)$ \\
\hline Current smoker & $238(45.3)$ & $124(46.3)$ & $118(44.2)$ \\
\hline Duration of smoking pack-yrs & $49.0 \pm 25.4$ & $48.0 \pm 24.0$ & $50.2 \pm 28.0$ \\
\hline \multicolumn{4}{|c|}{ Patients on different COPD medications prior to start of study ${ }^{\#}$} \\
\hline LAMA & $134(25.5)$ & $66(24.6)$ & $92(34.5)$ \\
\hline Post-bronchodilator FEV1 L & $1.5 \pm 0.5$ & $1.5 \pm 0.5$ & $1.5 \pm 0.5$ \\
\hline Post-bronchodilator FEV1 \% pred & $55.7 \pm 13.0$ & $56.4 \pm 14.0$ & $56.0 \pm 13.0$ \\
\hline Post-bronchodilator FEV1 reversibility \% & $16.2 \pm 15.2$ & $14.6 \pm 14.5$ & $16.4 \pm 14.5$ \\
\hline Post-bronchodilator FEV 1 /FVC \% & $50.6 \pm 10.5$ & $50.9 \pm 10.5$ & $50.3 \pm 10.5$ \\
\hline
\end{tabular}

Data are presented as mean \pm SD or $n(\%)$, unless otherwise stated. COPD: chronic obstructive pulmonary disease; GOLD: Global Initiative for Chronic Obstructive Lung Disease; ICS: inhaled corticosteroid; LAMA: long-acting muscarinic antagonist; LABA: long-acting $\beta_{2}$-agonist; SABA: short-acting $\beta_{2}$-agonist; SAMA: short-acting muscarinic antagonist; FEV1: forced expiratory volume in $1 \mathrm{~s}$; \% pred: \% predicted; FVC: forced vital capacity. Pack-yrs refers to the total years of smoking multiplied by cigarette packs smoked per day. COPD exacerbation history is the number of moderate or severe COPD exacerbations in the year prior to screening. Severity of COPD is classified based on per cent predicted FEV 1 and FEV $1 / F V C$ post-bronchodilation at the screening visit. Per cent predicted FEV 1 is obtained as a percentage of $F E V_{1}$ relative to the predicted normal value. ${ }^{\#}:>1 \%$ of total patients.

treatment difference of 0.81 (95\% CI 0.299-1.320; $\mathrm{p}=0.002)$. This was comparable to the improvement seen in the tiotropium group versus placebo (LSM treatment difference: $0.94,95 \%$ CI $0.356-1.521 ; p=0.002$; table 2, online supplement fig. S2a). The percentage of patients achieving a minimum clinically important difference (MCID; $\geqslant 1$ point improvement) [10] in TDI score at week 26 was significantly higher with NVA237 versus placebo (55.3 versus 44.2\%; OR 1.58, 95\% CI 1.118-2.245; $\mathrm{p}=0.01$ ) and also with tiotropium versus placebo (53.4 versus 44.2\%; OR 1.54, CI 1.038-2.295; $\mathrm{p}=0.032$ ) (online supplement fig. S2b). The LSM difference in TDI focal score versus placebo was also significantly superior with NVA237 at weeks 12 and $52(\mathrm{p}=0.024$ and $\mathrm{p}=0.038$, respectively), and with tiotropium at week 52 ( $\mathrm{p}=0.037$; table 2$)$. 


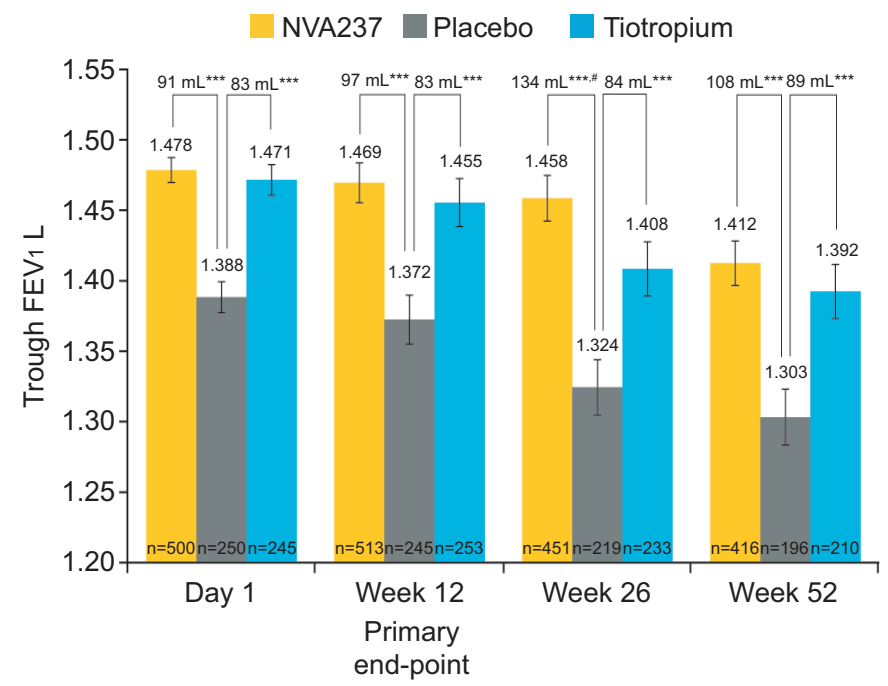

FIGURE 3. Trough forced expiratory volume in $1 \mathrm{~s}(\mathrm{FEV} 1)$ at day 1 and weeks 12, 26 and 52. Data presented as least squares mean $\pm \mathrm{SE}$. ${ }^{* *}: \mathrm{p}<0.001$ versus placebo; ${ }^{*}: p=0.007$ versus tiotropium.

\section{Health status}

SGRQ total score at week 52 was significantly improved in patients receiving NVA237 and tiotropium, with a LSM treatment difference versus placebo of -3.32 (95\% CI -5.287- -1.346; $\mathrm{p}<0.001)$ for NVA237 and $-2.84(95 \%$ CI $-5.105--0.571 ; \mathrm{p}=0.014)$ for tiotropium (table 2; online supplement fig. S3). A numerically higher proportion of patients achieved the MCID in total score ( $\geqslant 4$ point reduction) [11] with NVA237 (54.3\%) and tiotropium $(59.4 \%)$ versus placebo $(50.8 \%)$. The LSM treatment differences in SGRQ total score for NVA237 and tiotropium versus placebo were also significant at weeks 12 and 26 (table 2; online supplement fig. S3).

\section{Exacerbations and rescue medication}

NVA237 $50 \mu \mathrm{g}$ q.d. significantly reduced the risk of exacerbations in terms of time to first moderate or severe exacerbation by $34 \%$ compared with placebo (hazard ratio (HR) $0.66,95 \% \mathrm{CI}$ $0.520-0.850 ; p=0.001$; number needed to treat (NNT) 13.27) over 52 weeks (fig. 5). NVA237 demonstrated results comparable to tiotropium which provided a $39 \%$ risk reduction versus placebo (HR 0.61, 95\% CI 0.456-0.821; $\mathrm{p}=0.001$; NNT 10.04). A $34 \%$ reduction was observed in the rate of moderate or severe COPD exacerbations in the NVA237 group compared to placebo $(0.54$ versus 0.80 per yr; rate ratio $0.66,95 \%$ CI $0.496-0.869 ; \mathrm{p}=0.003$ ). The effect of tiotropium was not significantly different from placebo (rate ratio $0.80,95 \%$ CI $0.586-1.105 ; \mathrm{p}=0.179$ ).

NVA237 $50 \mu \mathrm{g}$ q.d. and tiotropium $18 \mu \mathrm{g}$ q.d. were comparable and were both superior to placebo in reducing moderate exacerbations requiring systemic corticosteroids (NVA237/ placebo OR $0.61,95 \%$ CI $0.434-0.870 ; \mathrm{p}=0.006$; tiotropium/ placebo OR 0.62, 95\% CI 0.413-0.930; p=0.021) and those requiring treatment with antibiotics (NVA237/placebo OR 0.69, 95\% CI 0.495-0.957; $\mathrm{p}=0.026$; tiotropium/placebo OR $0.65,95 \%$ CI $0.438-0.949 ; \mathrm{p}=0.026)$.

The use of rescue medication was significantly lower in patients receiving NVA237 and tiotropium versus those receiving placebo, with a between group treatment difference of 0.37 puffs per day $(p=0.039)$ and 0.63 puffs per day $(p=0.003)$, respectively (table 2 ).

\section{Safety}

The overall incidence of adverse events was similar across the three treatment groups (NVA237 76.6\%, placebo 76.5\%, tiotropium $74.2 \%$; table 3 ). The most frequently reported adverse event was COPD worsening, seen with a higher frequency in the placebo group (43.3\%) compared to the NVA237 and tiotropium groups (36.4 and $33.7 \%$, respectively). Anti-muscarinic sideeffects, such as dry mouth, constipation, urinary retention and urinary tract infections, occurred with a low frequency in the NVA237, placebo and tiotropium treatment groups.

Serious adverse events occurred with a lower frequency in the NVA237 group, compared with the tiotropium and placebo groups (table 3 ). COPD exacerbation was the most common serious adverse event, occurring in $6 \%$ of placebo patients, compared to $4.9 \%$ of tiotropium and $3.6 \%$ of NVA237 patients. Atrial fibrillation (AF) occurred more frequently in the NVA237 group compared to placebo (four patients $(0.8 \%$ ) versus 0 , respectively); two of the four patients had a co-existing history of AF and a third patient had a history of cardiac morbidity; none of the AF events were suspected to be related to the study medication. The percentage of patients with newly occurring or worsening clinically notable QTcF values (QT interval with Fridericia's correction) was low across treatment groups (NVA237 4.4\%, tiotropium 5.3\% and placebo $6 \%$ ).

Seven deaths were reported during the treatment and the 30day follow-up period; three in the NVA237 group (0.6\%) and two each in the placebo $(0.7 \%)$ and tiotropium groups $(0.7 \%)$. None of the deaths was suspected to be related to the study medication.

\section{DISCUSSION}

Results from the GLOW2 study demonstrated that once-daily NVA237 $50 \mu \mathrm{g}$ is an efficacious and safe LAMA in patients with COPD over 52 weeks of treatment, and is comparable to tiotropium, the current gold standard for the treatment of COPD. Trough FEV1 at day 1 and at weeks 12 (primary endpoint), 26 and 52 with NVA237 was significantly superior versus placebo. NVA237 also significantly improved dyspnoea at week 26 (mean treatment difference in TDI focal score: 0.81 ; $p=0.002$ ), health status at week 52 (mean treatment difference in SGRQ total score: $-3.32 ; \mathrm{p}<0.001$ ), and reduced the risk of moderate-to-severe COPD exacerbations $(\mathrm{p}=0.001)$ and the use of rescue medication $(p=0.039)$, versus placebo. NVA237 was well tolerated, and displayed a safety profile comparable to placebo and tiotropium.

There is evidence to suggest that patients with COPD struggle to undertake morning activities; symptoms, particularly dyspnoea and activity limitation, are most challenging in the mornings [12]. In the GLOW2 study, NVA237 provided rapid bronchodilation following the first dose on day 1; FEV1 from 5 min to $4 \mathrm{~h}$ post-dose was significantly higher versus placebo at day 1 and also at weeks 12, 26 and $52(\mathrm{p}<0.001)$, and versus tiotropium at day 1 and week $26(\mathrm{p}<0.05)$. Further, the rapid bronchodilation produced by NVA237 was sustained over the 24-h period on day 1 and weeks 12, 26 and 52. A rapid onset of 
TABLE 2 Spirometry and symptom-related (dyspnoea, health status, rescue medication use) outcomes on day 1 and weeks 12 26 and 52 (full analysis set population)

Treatment difference

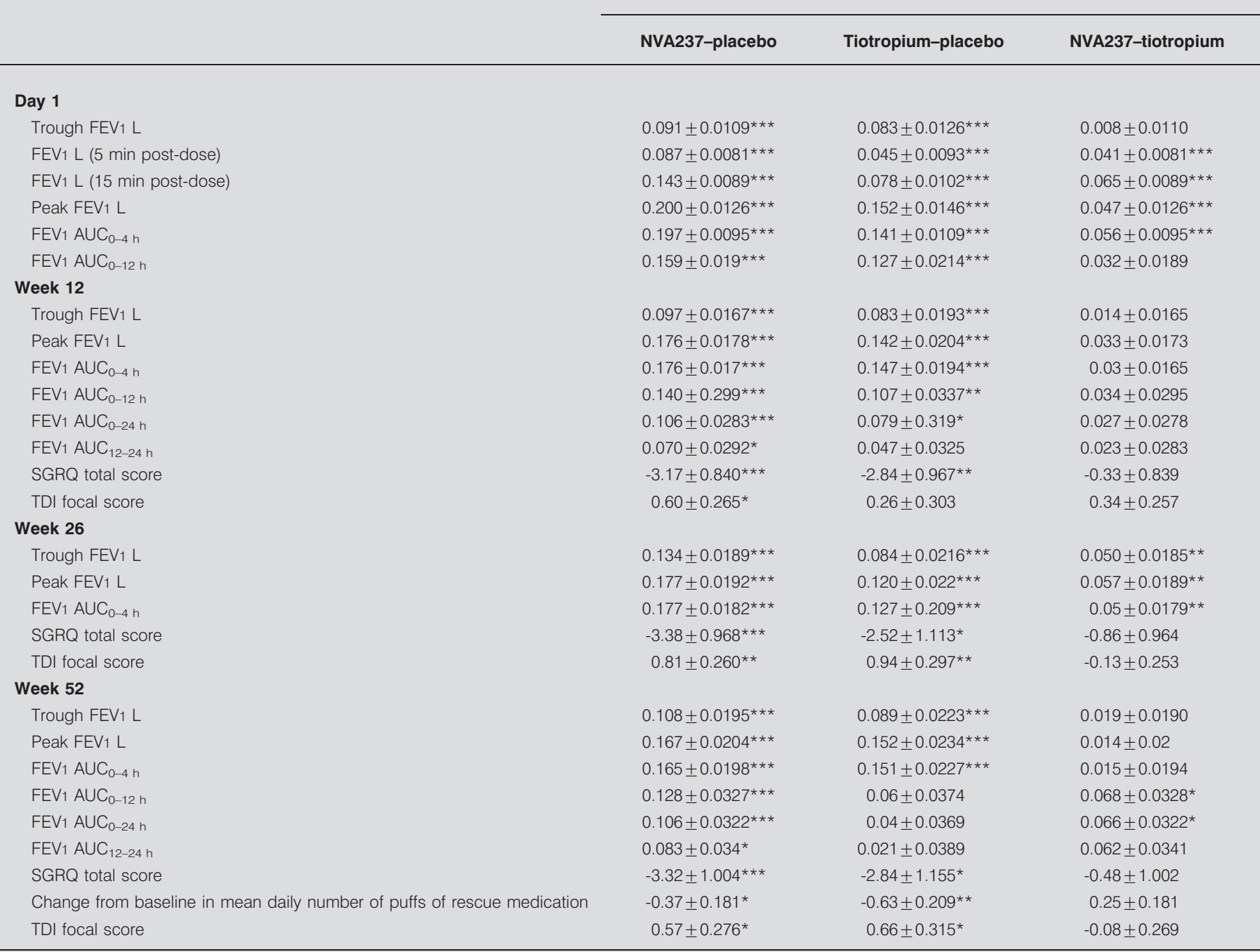

Data are presented as least squares mean \pm SE. FEV1: forced expiratory volume in $1 \mathrm{~s}$; AUC: area under the curve; TDI: Transition Dyspnoea Index; SGRQ: St George's Respiratory Questionnaire. ${ }^{* * *}: p<0.001 ;{ }^{* *}: p<0.01 ;{ }^{*}: p<0.05$.

effect and sustained 24-h bronchodilation are important features which may have a significant positive impact on the morning routines and daily life of patients with COPD, and could potentially contribute to improving adherence to therapy.

The GOLD guidelines recognise the importance of symptom reduction in the management of COPD, and the assessment of symptom severity is a key element in the pharmacological management of COPD [2]. Exertional dyspnoea is one of the most distressing symptoms for patients with COPD [13]. Lung hyperinflation reduces inspiratory capacity, a measure that correlates with dyspnoea and exercise tolerance in patients with moderate-to-severe COPD [13]. In the GLOW3 study, NVA237 $50 \mu \mathrm{g}$ produced significant improvements in inspiratory capacity at isotime (defined as the last matching time point in submaximal exercise tolerance test at which for both periods the patient had a test result) at day 1 , which was sustained through the study period of 3 weeks (both $p<0.001$ ) [14]. This was accompanied by an immediate and significant improvement in exercise endurance from day 1 , which increased over the study period (both $p<0.001$ ). In the current GLOW2 study, the significantly greater improvement in inspiratory capacity seen with NVA237 versus placebo (comparable to improvement provided with tiotropium versus placebo) signifies a greater reduction in hyperinflation, which may contribute to a reduction in dyspnoea. Furthermore, NVA237 produced an improvement in dyspnoea on the TDI that was superior to placebo and comparable to tiotropium at weeks 12, 26 and 52. The reduced usage of rescue medication in patients receiving NVA237 compared with placebo also indicates better symptom management. This overall improvement was reflected in the SGRQ total scores which were 

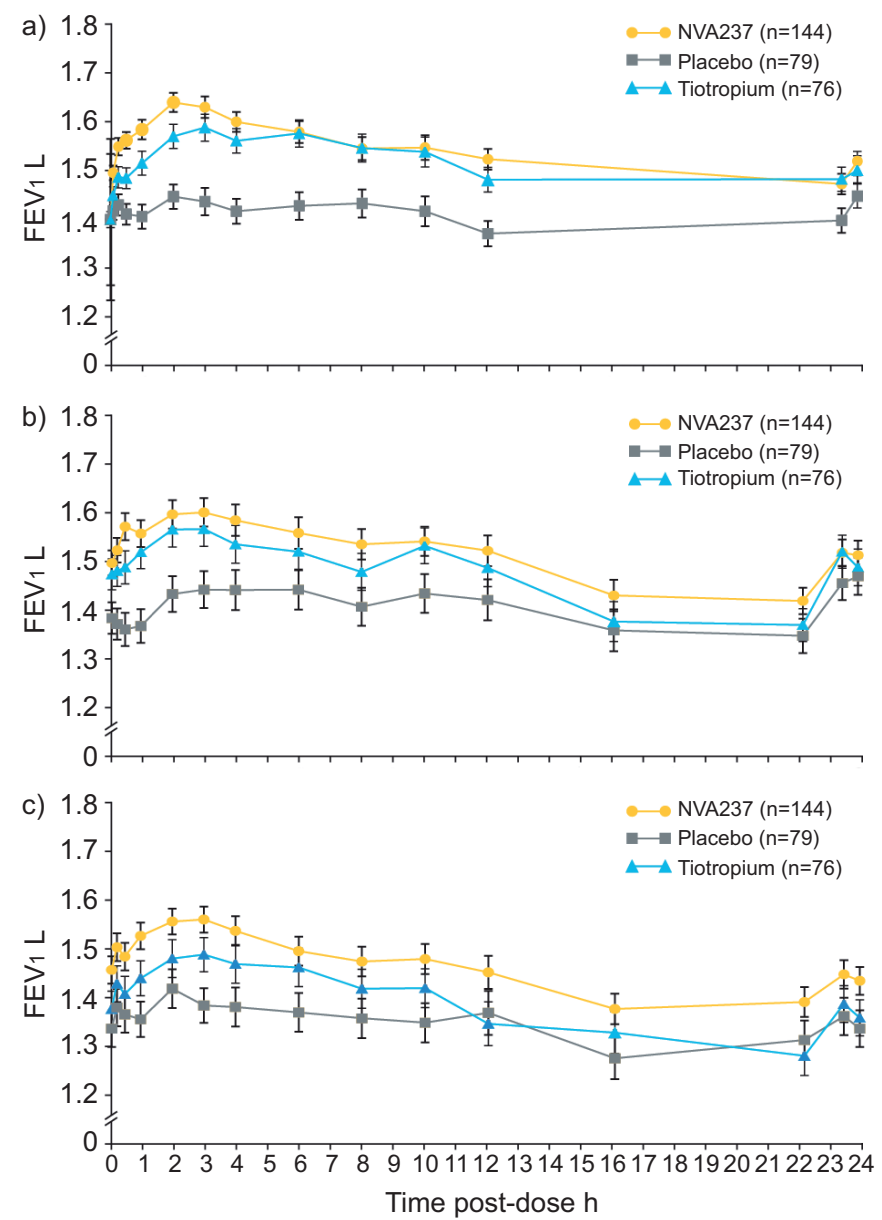

FIGURE 4. Serial spirometry on a) day 1, b) week 12 and c) week 52. a) NVA237 superior to placebo at all assessed time points $(p<0.01)$, superior to tiotropium at 5, 15 and $30 \mathrm{~min}, 1$ and $2 \mathrm{~h}(\mathrm{p}<0.05)$. b) NVA237 versus placebo all time points statistically significant $(p<0.05)$ except $16 \mathrm{~h}, 23 \mathrm{~h} 15 \mathrm{~min}$ and $23 \mathrm{~h}$ 45 min. c) NVA237 superior to placebo at all assessed time points $(p<0.01)$, superior to tiotropium at $5 \mathrm{~min}, 15 \mathrm{~min}$ and $30 \mathrm{~min}$, and 1,2 and $3 \mathrm{~h}(\mathrm{p}<0.05)$. FEV1: forced expiratory volume in $1 \mathrm{~s}$.

significantly lower with NVA237 and comparable to tiotropium, versus placebo, at weeks 12 and 52.

COPD exacerbations reduce patients' health status [15, 16], and increase the risk of hospitalisation and death [17, 18], and treatment costs [19]. Furthermore, an association has been reported between frequency of exacerbations and increased rate of lung function decline [20, 21]. Hence, prevention of exacerbations and reduction of future risk should be a consideration in the management of COPD [2]. In the GLOW2 study, NVA237 reduced the risk of moderate-to-severe COPD exacerbations in patients with COPD by $34 \%$ versus placebo. The NNT to avoid one moderate-to-severe exacerbation in patients with COPD over 52 weeks with NVA237 versus placebo was 13.27; it was comparable to the NNT with tiotropium versus placebo (10.04). It is noteworthy that in the GLOW2 study, a majority of the patients $(>63 \%)$ had moderate COPD, and only a minority $(27 \%)$ had a baseline history of exacerbations. This makes the improvement seen in COPD exacerbations more

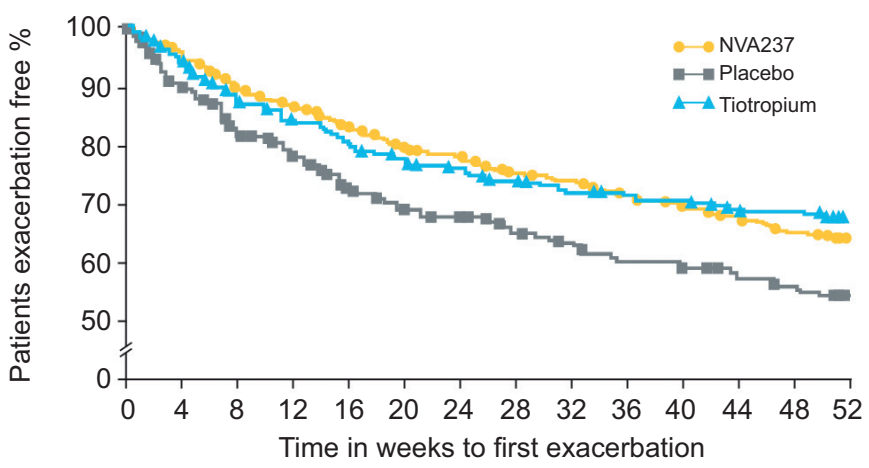

Number at risk

$\begin{array}{llllllllllllll}\text { NVA237 } & 495 & 451 & 426 & 394 & 370 & 360 & 341 & 335 & 318 & 310 & 296 & 282 & 239\end{array}$ $\begin{array}{llllllllllllll}\text { Placebo } & 229 & 202 & 188 & 168 & 159 & 153 & 142 & 137 & 129 & 129 & 122 & 116 & 98\end{array}$

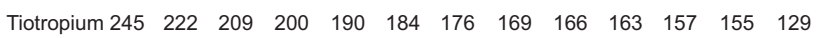

FIGURE 5. Kaplan-Meier plot of the time to first moderate or severe chronic obstructive pulmonary disease exacerbation.

significant, since it might indicate that the beneficial effects of NVA237 on exacerbations could apply across a broad COPD population, not just patients with severe COPD or a history of frequent exacerbations. It should be noted that the GLOW2 study was not powered to analyse the rate of exacerbations and the study population was not enriched by recruiting patients with frequent exacerbations. Also, the lower baseline exacerbation history in patients in the GLOW2 study compared with the ECLIPSE study, in which $39 \%$ of patients with moderate COPD and $52 \%$ of those with severe COPD had one or more exacerbations during the past year [22], could potentially be due to different criteria used for defining exacerbations in the two studies; in the GLOW2 study pre-defined criteria needed to be met for an event to be classified as an exacerbation, while the ECLIPSE study had no such criteria.

The safety profile of NVA237 $50 \mu \mathrm{g}$ q.d. observed in the current study was consistent with the known safety profile of NVA237 and was comparable to the safety profile of tiotropium. Antimuscarinic side-effects, such as dry mouth, constipation, urinary retention and urinary tract infections, occurred with a low frequency in all treatment groups. Overall, NVA237 $50 \mu \mathrm{g}$ q.d. was generally well tolerated over a longer treatment period of 52 weeks.

Tiotropium, being the only once-daily LAMA currently available for COPD, was an appropriate control for the GLOW2 study since it provides a degree of validation for characterisation to a well-studied bronchodilator. However, technical difficulties make it difficult to blind tiotropium in clinical trials: tiotropium is a hygroscopic powder that cannot be removed from the commercial capsules (marked with a logo) for repackaging into unmarked capsules. A potential limitation of the GLOW2 study was the inability to blind tiotropium treatment, raising the possibility of bias in comparing the results for NVA237 with those of tiotropium.

In open-label study designs, there is a possibility that patients on unblinded active drugs may report more favourable outcomes because they expect a benefit; previous experience with the unblinded comparator may also affect their reporting of subjective efficacy end-points or adverse effects. In the 
TABLE 3 Most frequent adverse events ( $\geqslant 3 \%$ in any treatment group), serious adverse events occurring in $\geqslant 3$ patients in either group, deaths and discontinuations due to adverse events and electrocardiographic abnormalities

\begin{tabular}{|c|c|c|c|}
\hline & NVA237 $50 \mu \mathrm{g}$ q.d. & Placebo & Tiotropium $18 \mu \mathrm{g}$ q.d. \\
\hline Subjects $\mathbf{n}$ & 525 & 268 & 267 \\
\hline COPD worsening ${ }^{\#}$ & $191(36.4)$ & $116(43.3)$ & $90(33.7)$ \\
\hline Upper respiratory tract infection & $57(10.9)$ & $33(12.3)$ & $30(11.2)$ \\
\hline Nasopharyngitis & $47(9.0)$ & $15(5.6)$ & $21(7.9)$ \\
\hline Back pain & $25(4.8)$ & $10(3.7)$ & $12(4.5)$ \\
\hline Headache & $25(4.8)$ & $14(5.2)$ & $12(4.5)$ \\
\hline Lower respiratory tract infection & $23(4.4)$ & $9(3.4)$ & $10(3.7)$ \\
\hline Bronchitis & $22(4.2)$ & $10(3.7)$ & $12(4.5)$ \\
\hline Cough & $21(4.0)$ & $13(4.9)$ & $12(4.5)$ \\
\hline Urinary tract infection & $14(2.7)$ & $8(3.0)$ & $16(6.0)$ \\
\hline Peripheral oedema & $9(1.7)$ & $6(2 . .2)$ & $8(3.0)$ \\
\hline Upper respiratory tract infection viral & $9(1.7)$ & $13(4.9)$ & $11(4.1)$ \\
\hline Patients with serious adverse events & $66(12.6)^{\bullet}$ & $43(16.0)$ & $41(15.4)^{\bullet}$ \\
\hline COPD worsening ${ }^{\#}$ & $19(3.6)$ & $16(6.0)$ & $13(4.9)$ \\
\hline Pneumonia & $7(1.3)$ & $7(2.6)$ & $4(1.5)$ \\
\hline Atrial fibrillation & $4(0.8)$ & 0 & 0 \\
\hline Dehydration & $4(0.8)$ & $2(0.7)$ & 0 \\
\hline Syncope & $3(0.6)$ & $1(0.4)$ & 0 \\
\hline Transient ischemic attack & $3(0.6)$ & $1(0.4)$ & 0 \\
\hline Bronchitis & $3(0.6)$ & $1(0.4)$ & 0 \\
\hline
\end{tabular}

Data are presented as $n(\%)$, unless otherwise stated. ${ }^{\#}$ : includes chronic obstructive pulmonary disease (COPD) exacerbation; ${ }^{\circ}$ : includes one serious adverse event in the 30-day follow-up period; ${ }^{+}$: includes one death in the 30 -day follow-up period.

GLOW2 study, the open-label nature of the comparison with tiotropium could have mildly influenced the results of the patient-reported outcomes or rescue medication usage. However, the primary and the majority of the secondary efficacy objectives in the GLOW2 study were based on spirometric endpoints, with comparable results seen in the NVA237 and the tiotropium treatment groups, including serial spirometry in a subpopulation of patients, which demonstrated comparable efficacy profiles for NVA237 and tiotropium at week 12. Spirometry is considered to be an objective, standardised and reproducible measure of airflow limitation, and is not likely to be subject to bias. Furthermore, the results obtained in the GLOW2 study for tiotropium versus placebo in terms of improvements in lung-function, TDI and SGRQ scores were consistent with results from other randomised placebo-controlled trials using blinded tiotropium [23-30].
It may be pointed out that although the magnitude of improvement observed in trough FEV1 with tiotropium versus placebo was comparable to the improvement seen with tiotropium in recent randomised tiotropium trials [23-26], it was lower than the improvement observed in earlier such studies [27-29]. Some of the possible explanations could include differences in baseline demographics of patient population, shift in the baseline characteristics of patients entering trials due to benefits obtained from the variety of short- and long-acting bronchodilators currently available, as opposed to the limited options available previously, and selective recruitment due to the impact of concomitant medications permitted [31].

The results for NVA237 $50 \mu \mathrm{g}$ q.d. versus placebo in the GLOW2 study were comparable to those for tiotropium, suggesting that NVA23750 $\mu \mathrm{g}$ q.d. has the potential to be a useful alternative to tiotropium. 


\section{Conclusions}

The results from the GLOW2 study demonstrated that over 52 weeks, once-daily NVA237 $50 \mu \mathrm{g}$ has a rapid onset of action and sustained 24-h efficacy, and is safe and well tolerated. Once-daily NVA237 provided comparable efficacy to tiotropium, the current gold standard for the treatment of COPD, and could be an alternative LAMA choice for patients with COPD.

\section{SUPPORT STATEMENT}

The study was sponsored by Novartis Pharma AG.

\section{CLINICAL TRIAL}

Trial registration: ClinicalTrials.gov NCT00929110

\section{STATEMENT OF INTEREST}

A statement of interest for all authors, and for the study itself, can be found at www.erj.ersjournals.com/site/misc/statements.xhtml

\section{ACKNOWLEDGEMENTS}

The authors were assisted in the preparation of the manuscript by S. Mudgal, professional medical writer contracted to CircleScience (Macclesfield, UK), and M.J. Fedele (Novartis, East Hanover, NJ, USA). Writing support was funded by the study sponsor.

\section{REFERENCES}

1 Viegi G, Pistelli F, Sherrill DL, et al. Definition, epidemiology and natural history of COPD. Eur Respir J 2007; 30: 993-1013.

2 Global Initiative for Chronic Obstructive Lung Disease (GOLD 2011). Global Strategy for the Diagnosis, Management and Prevention of Chronic Obstructive Pulmonary Disease. Available from www.goldcopd.org

3 Cooper N, Walker I, Knowles I. NVA237 has similar efficacy as tiotropium bromide against methacholine-induced bronchoconstriction and less systemic effect on cardiovascular variables in an anaesthetized rabbit model. Eur Respir J 2006; 28: Suppl. 50, 436s.

4 Trifilieff A, Cope N, Boivin JF, et al. The inhaled antimuscarinic receptor antagonist, NVA237 (glycopyrrolate), has a favorable side-effect profile in a Brown Norway rat lung function model when compared with tiotropium. Chest 2007; 132: 530a.

5 Fogarty C, Hattersley H, Di Scala L, et al. Bronchodilatory effects of NVA237, a once-daily long-acting muscarinic antagonist, in COPD patients. Respir Med 2011; 105, 3: 337-342.

6 Verkindre C, Fukuchi Y, Flémale A, et al. Sustained 24-h efficacy of NVA237, a once-daily long-acting muscarinic antagonist, in COPD patients. Respir Med 2010; 104: 1482-1489.

7 Vogelmeier C, Verkindre C, Cheung D, et al. Safety and tolerability of NVA237, a once-daily long-acting muscarinic antagonist, in COPD patients. Pulm Pharmacol Ther 2010; 23: 438-444.

8 D'Urzo A, Ferguson GT, van Noord JA, et al. Efficacy and safety of once-daily NVA237 in patients with moderate-to-severe COPD: the GLOW1 trial. Respir Res 2011; 12: 156.

9 Global Initiative for Chronic Obstructive Lung Disease (GOLD 2008). Global Strategy for the Diagnosis, Management and Prevention of Chronic Obstructive Pulmonary Disease. Available from www.goldcopd.org.

10 Witek TJ Jr, Mahler DA. Minimal important difference of the transition dyspnoea index in a multinational clinical trial. Eur Respir J 2003; 21: 267-272.

11 Jones P, Lareau S, Mahler DA. Measuring the effects of COPD on the patient. Respir Med 2005; 99: Suppl. B, S11-S18.
12 Partridge MR, Karlsson N, Small IR. Patient insight into the impact of chronic obstructive pulmonary disease in the morning: an internet survey. Curr Med Res Opin 2009; 25: 2043-2048.

13 O'Donnell DE, Webb KA. The major limitation to exercise performance in COPD is dynamic hyperinflation. J Appl Physiol 2008; 105: 753-755.

14 Beeh KM, Singh D, Di Scala L, et al. Once-daily NVA237 improves exercise tolerance from the first dose in patients with COPD: the GLOW3 trial. Int J COPD 2012; 7: 503-513.

15 Spencer S, Calverley PM, Burge PS, et al. Impact of preventing exacerbations on deterioration of health status in COPD. Eur Respir J 2004; 23: 698-702.

16 Miravitlles M, Ferrer M, Pont A, et al. Effect of exacerbations on quality of life in patients with chronic obstructive pulmonary disease: a 2 year follow up study. Thorax 2004; 59: 387-395.

17 Seneff MG, Wagner DP, Wagner RP, et al. Hospital and 1-year survival of patients admitted to intensive care units with acute exacerbation of chronic obstructive pulmonary disease. JAMA 1995; 274: 1852-1857.

18 Vestbo J. What is an exacerbation of COPD? Eur Respir Rev 2004; 13: 6-13.

19 Andersson F, Borg S, Jansson SA, et al. The costs of exacerbations in chronic obstructive pulmonary disease (COPD). Respir Med 2002; 96: 700-708.

20 Donaldson GC, Seemungal TA, Bhowmik A, et al. Relationship between exacerbation frequency and lung function decline in chronic obstructive pulmonary disease. Thorax 2002; 57: 847-852.

21 Celli BR, Thomas NE, Anderson JA, et al. Effect of pharmacotherapy on rate of decline of lung function in chronic obstructive pulmonary disease: results from the TORCH study. Am J Respir Crit Care Med 2008; 178: 332-338.

22 Hurst JR, Vestbo J, Anzueto A, et al. Susceptibility to exacerbation in chronic obstructive pulmonary disease. N Engl J Med 2010; 363: 1128-1138.

23 Tashkin DP, Celli B, Senn S, et al. A 4-year trial of tiotropium in chronic obstructive pulmonary disease. N Engl J Med 2008; 359: 1543-1554.

24 Tonnel AB, Perez T, Grosbois JM, et al. Effect of tiotropium on health-related quality of life as a primary efficacy endpoint in COPD. Int J Chron Obstruct Pulmon Dis 2008; 3: 301-310.

25 Niewoehner DE, Rice K, Cote C, et al. Prevention of exacerbations of chronic obstructive pulmonary disease with tiotropium, a oncedaily inhaled anticholinergic bronchodilator: a randomized trial. Ann Intern Med 2005; 143: 317-326.

26 Chan CK, Maltais F, Sigouin C, et al. A randomized controlled trial to assess the efficacy of tiotropium in Canadian patients with chronic obstructive pulmonary disease. Can Respir J 2007; 14: 465-472.

27 Donohue JF, van Noord JA, Bateman ED, et al. A 6-month, placebo-controlled study comparing lung function and health status changes in COPD patients treated with tiotropium or salmeterol. Chest 2002; 122: 47-55.

28 Casaburi R, Mahler DA, Jones PW, et al. A long-term evaluation of once-daily inhaled tiotropium in chronic obstructive pulmonary disease. Eur Respir J 2002; 19: 217-224.

29 Brusasco V, Hodder R, Miravitlles M, et al. Health outcomes following treatment for six months with once daily tiotropium compared with twice daily salmeterol in patients with COPD. Thorax 2003; 58: 399-404.

30 Decramer M, Celli B, Kesten S, et al. Effect of tiotropium on outcomes in patients with moderate chronic obstructive pulmonary disease (UPLIFT): a prespecified subgroup analysis of a randomised controlled trial. Lancet 2009; 374: 1171-1178.

31 Donohue JF, Jones PW. Changing patterns in long-acting bronchodilator trials in chronic obstructive pulmonary disease. Int J Chron Obstruct Pulmon Dis 2011; 6: 35-45. 